\title{
Pasiones, sueños y conversaciones
}

\author{
Xóchitl Leyva
}

JAN DE VOS, 2002

\section{Una tierra para sembrar sueños. Historia} reciente de la selva Lacandona, 1950-2000

FCE y CIESAS, México.

\section{I) Las voces} \section{$\left(\begin{array}{l}\text { na tierra para sembrar sueños se } \\ \text { suma a un concierto de voces }\end{array}\right.$} universales que, sobre todo, desde 1994 han cantado con diferentes ritmos y a diferentes tonos a la Lacandona y sus habitantes. Dentro de esas voces se encuentran la del ensayista descendiente de don Porfirio, la de la asesora agraria socióloga, la de los misioneros católicos, la del obispo "libertario", la de los antropólogos pioneros, la de los periodistas "anti-marquistas",

XÓCHITL LEYVA: CIESAS.

Desacatos, núm. 11, primavera 2003 , pp. 190-192. la de los subcomandantes indígenas, la del novelista catalán de "izquierdas", la del líder guerrillero mestizo urbano posmoderno, la del Nobel de literatura, la de la ex primera dama francesa, etcétera, etcétera. En pocas palabras, Una tierra para sembrar sueños no está sola y de hecho retoma temas ya abordados por otros. Estos temas van desde la colonización, el refugio guatemalteco y las confluencias étnico-religiosas hasta el surgimiento del EZLN, la deforestación y el "conflicto de La Brecha". Pero una vez dicho esto uno se preguntaría por qué entonces recomendar leer Una tierra para sembrar sueños. Pues bien, porque Jan Vos en ese libro hace una síntesis sobre lo que se ha dicho acerca de esos temas a lo cual agrega información novedosa después de revisar minuciosamente fuentes que otros dejaron de lado $o$ simplemente no llegaron a conocer. De Vos también condimenta su escritura con vivencias personales que tuvo a lo largo de más de dos décadas de trabajar como "historiador regional" de la selva. Todo esto hace de Una tierra para sembrar sueños una voz privilegiada en el concierto universal de las voces que hoy cantan, alaban, mitifican, la selva Lacandona.

\section{II) Los sueños}

Una tierra para sembrar sueños es una obra bien escrita y bien ilustrada que cobra doble importancia al cerrar el ciclo personal y profesional de Jan de Vos como apasionado de la selva y como "historiador regional" que ha mirado la Lacandonia con todos sus sentidos desde la Colonia hasta los albores del siglo XXI. Nadie como él ha realizado proeza tan grande. Pero la relevancia del libro hoy reseñado no termina aquí, es también importante 
porque hila muchos cabos sueltos que no existían unidos en un solo texto.

De Vos retoma, sobre todo en el capítulo II, el camino que dejó abierto al final de su obra Oro verde (1998) en la cual detenía el tiempo selvático en 1949 cuando se retiraron de la zona los madereros tabasqueños. En Una tierra para sembrar sueños, de Vos (a la luz de nuevas investigaciones agrarias, documentos y testimonios) replantea algunas ideas sobre los flujos de la colonización: fechas de inicio, formas, rutas, redes, corrupciones, amiguismos, afectaciones a viejos madereros, fracasos de empresarios extranjeros, etc., etc., dándonos así nuevas luces sobre la cuestión agraria y forestal de la selva contemporánea. La primera (la cuestión agraria) poco trabajada entre 1930 y 1994; y la segunda (la cuestión forestal), abundante en fuentes pero poco sistematizadas hasta la fecha.

En Una tierra para sembrar sueños Jan, haciendo gala de sus dotes de historiador, nos lleva desde los archivos de la Secretaría de la Reforma Agraria, de la Empresa Forestal "Maderera Maya", de la familia Bulnes hasta los de las organizaciones de base como el "CDLI" o la misma "ARIC Unión de Uniones”. A la par, Jan introduce sus vivencias personales, sintetiza libros y artículos académicos, retoma folletos, notas, cuadernos inéditos, informes, "diagnósticos" y leyes escritas entre 1950 y 1999 que estaban dispersas o que eran totalmente desconocidas por un público numeroso.

De Vos nos ofrece en su libro una mirada diferente y bien documentada sobre la tan manoseada historia reciente de los habitantes de la selva

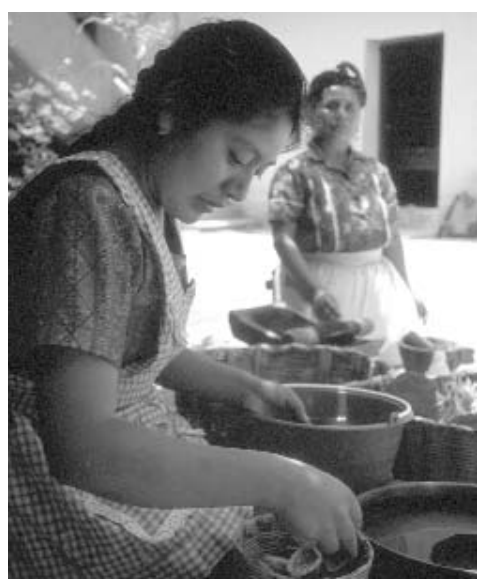

Señora artesana; Teotitlán del Valle, Oaxaca, 1999 / Roxana Acevedo

Lacandona. Más allá de la historia de héroes de bronce, de Vos nos presenta historias de hombres que sueñan, que pertenecen a colectividades y que hacen de la selva eso, una tierra sembrada de sueños. Recrea imaginarios individuales-colectivos, expectativas, esperanzas, utopías que llama sueños y que pertenecen tanto a mestizos como a indígenas, a madereros como a campesinos, a mexicanos como a guatemaltecos.

No pudo haber mejor selección de personajes que la que hiciera Jan para mostrar el mosaico humano que habitó y habita la selva. El descendiente de maderero que quiere parar la "colonización desordenada" a través de una “empresa forestal moderna”, sueña al lado de la fotógrafa suiza protectora tanto de lacandones como de antropólogos de la época. En seguida viene el sueño del descendiente del latifundista asturiano Canuto Bulnes, quien más que vivir como opulento finquero cuando Jan lo llegó a visitar en 1985, habitaba en un "ranchito" cercano a la Laguna de Miramar. Luego vienen los colonos-campesinos y sus sueños de liberación a través de la teología india, de las Fuerzas de Liberación Nacional y de las organizaciones campesinas “independientes". En seguida tenemos a la refugiada guatemalteca que vive en el exilio la pesadilla de las masacres y sueña con el retorno a su tierra. Cierran la lista los sueños zapatistas del mestizo y del indígena. De Vos con todo ello nos quiere demostrar "las múltiples selvas Lacandonas" que encontró "moldeadas según los intereses y preocupaciones de quienes se acercaron a ella” (p. 1).

Una tierra para sembrar sueños será para todo lector una fuente inagotable de inspiración. Para el no especialista de seguro hará las veces de un compendio de cinco lustros de escritos, vivencias y sueños selváticos. Para el especialista facilitará el camino del conocimiento y con ello contribuirá a crecer el debate histórico, político y académico en torno y sobre la selva Lacandona.

\section{III) Las conversaciones}

No cabe la menor duda de que la lectura de un libro es antes que nada una conversación orientada por los intereses del lector $y$, en ese sentido, no puedo dejar de mencionar que en Una tierra para sembrar sueños encontré motivos suficientes para seguir conversaciones colectivas y debates en torno a la sui generis cuestión agraria de la selva Lacandona. Me llamaron la atención en particular los sueños del montero y escritor Pedro Vega y de Jaime Bulnes Flanagan, heredero de un latifundista español. A través 
de sus testimonios uno conoce de viva voz cómo propietarios ausentistas o herederos latifundistas de la selva no quisieron, o bien no pudieron, defenderse de la expropiación agraria posrevolucionaria cuando en otras regiones de Chiapas la reforma agraria no tocó los intereses de importantes familias latifundistas. Este trato diferencial a los grandes propietarios de las distintas regiones de Chiapas podría explicarse al recordar que la selva fue la última frontera usada como válvula de escape para resolver las demandas agrarias de muchas partes del estado y del país.

Me parece también muy acertado que Jan haya incluido como parte del tejido actual selvático el sueño de una mujer refugiada guatemalteca. Ya no se debiera, creo yo, hablar de los refugiados como un mundo en sí mismo, encapsulado en sus "campos", sino verlos como piezas claves de una historia fronteriza, selvática, político-militar compartida y diferente. No quiero decir que no se haya escrito suficiente sobre los "refugiados guatemaltecos"; por el contrario, se ha escrito mucho pero a mi juicio lo que ha hecho falta es explorarles como actores mexicanos, o mejor dicho, como actores binacionales de gran envergadura, como bisagras político-culturales de la frontera sur. Aunque en Una tierra para sembrar sueños Jan no vincula la guerra guatemalteca con la [neo]zapatista, sí invita a pensar con más detenimiento en esto $\mathrm{y}$ abre muchas preguntas para futuras investigaciones.

De Vos cierra su libro doliéndose de la deforestación de la selva y criticando la militarización excesiva de la misma. Militarización que, enfatiza, ha contribuido al crecimiento del divisionismo comunitario. El autor señala con certeza que para hacer frente a las políticas neoliberales venideras se requiere, antes que nada, restaurar el tejido social de las comunidades indígenas así como "preservar" los recursos naturales de la selva. Esto último sería la mejor manera de celebrar la memoria de los tres personajes no indígenas que escogió de Vos para su libro: el montero-escritor, la fotógrafa suiza lacandófila y la del maderero-ranchero. Todos ellos "pasaron los últimos años de su vida viendo transformarse sus sueños [conservacionistas] en [verdaderas] pesadillas" (p. 398).

Por lo que toca a los sueños de los otros cinco personajes indígenas que se incluyen en el libro, Jan nos dice que éstos de alguna manera vieron transformar sus anhelos en realidades. Transformaciones que no fueron fortuitas sino producto de muchos años de esfuerzos organizativos y de lucha política.

\section{IV) Las pasiones}

De Vos llegó a México y supo escudriñar lo mismo en la vida de los indios como en la de los latifundistas; puso así a nuestro alcance voces, documentos, testimonios y fotografías que habían estado calladas y ocultas, pero lo más sorprendente es que a través de su trilogía selvática (La paz de Dios, Oro verde y el libro que aquí se reseña) uno puede, a manera de rompecabezas, llegar a armar el propio sueño del autor, sueño que comparte con muchos indígenas politizados de la selva Lacandona y de Chiapas. Pero esto que para algunos podría ser visto como una virtud puede convertirse en motivo de controversia y crítica. De hecho, desde su primera presentación en Chiapas, Una tierra para sembrar sueños ya empezó a levantar pasiones entre actores de los diferentes procesos políticos de las tres últimas décadas. Esto no resulta extraño, pues en Chiapas hay cientos de historias no contadas que en Una tierra para sembrar sueños encontrarán no sólo un interlocutor sino una voz distinta y perturbadora.

Para finalizar de Vos señala la necesidad - y agregaría yo un tanto de manera inocente, urgentísima - de conocer de viva voz la historia de la participación de los indígenas en los recientes procesos político-militares. Esto, cuando suceda, nos abrirá sin duda nuevas formas de concebir no sólo la Lacandona sino lo que hasta ahora hemos dado en llamar "el conflicto chiapaneco".

\section{Epílogo}

Quisiera concluir diciendo lo que ya he dicho en otros foros: ahora que las políticas neoliberales parecieran que sólo se interesan por la docencia y la investigación mercantilizadas, que bailan al son de los dólares o de la empresa privada, de Vos está ahí con su trilogía selvática (con su tríptico flamenco como diría Mario Humberto Ruz) para recordarnos y demostrarnos que para ser "de excelencia" no se necesita más que una buena dosis de sensibilidad, honestidad, arduo trabajo y mucha pasión. 